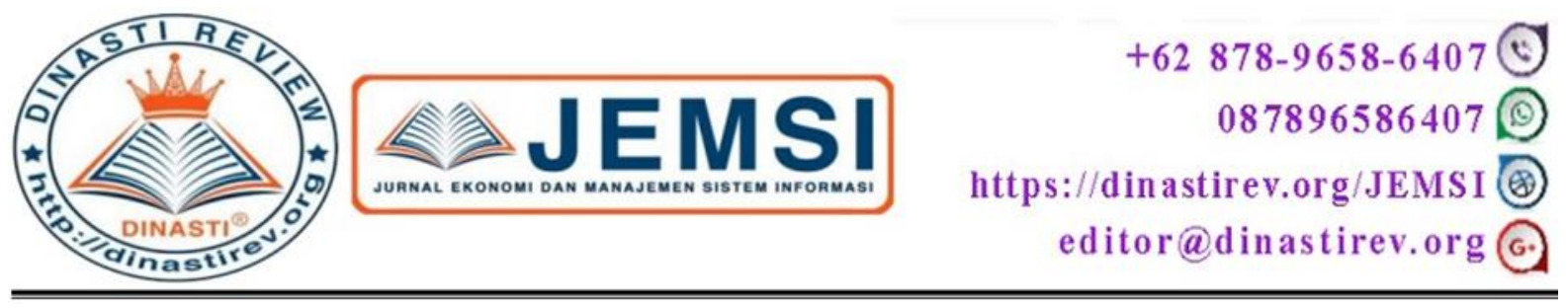

ANALISIS STRATEGI BERSAING DALAM PERSAINGAN USAHA SPECIALITY TEA (STUDI KASUS BRAND "SILA" PT SILA AGRI INOVASI)

\title{
Ruspriono Soenaryo
}

Universitas Mercu Buana, Jakarta, Indonesia

ARTICLE INFORMATION

Received: 4 Mei 2020

Revised: 20 Juni 2020

Issued: 19 Juli 2020

Corresponding author: first author E-mail: ruspriono@gmail.com



DOI:10.31933/JEMSI
Abstrak: Masyarakat Indonesia mungkin dikenal dengan speciality coffee. Sama halnya dengan kopi, industri teh dunia juga mengenal speciality tea alias teh unggulan. Speciality tea adalah teh yang melalui proses spesial di mulai dari penanaman pemetikan, dan proses sehingga punya karakteristik teh yang berbeda. PT SILA Agri Inovasi membuka usaha di bidang inovasi produk hasil pertanian Indonesia khususnya Speciality tea didasari oleh lemahnya inovasi di bidang hasil pertanian Indonesia, Nilai tambah baik berupa pendapatan dan keuntungan usaha ada di industri hilir yang berbasis inovasi, Pengalaman para pendiri di berbagai perusahaan industri hilir menjadi aset intelektual bagi usaha ini. Tujuan penelitian ini adalah untuk mengetahui dan menganalisis secara kualitatif strategi bersaing yang dijalankan oleh PT SILA Agri Inovasi melalui brand SILA. Metode penelitian adalah kualitatif deskriptif berupa penelitian dengan metode atau pendekatan studi kasus (CaseStudy). Hasil penelitian yaitu SAI melakukan strategi usaha dengan strategi Winning Organization, Winning Brand, Winning in Distribution dan Winning in Supply Chain.

Kata Kunci: Strategi Bersaing. Speciality Tea, Brand

\section{PENDAHULUAN}

Komoditas teh memiliki peranan penting dalam perekonomian nasional yaitu sebagai sumber pendapatan bagi petani, membuka lapangan pekerjaan, sumber devisa Negara, mendorong agroindustri pengembangan wilayah dan pelestarian lingkungan. Pada umumnya tanaman teh nasional dikembangkan di Indonesia sejak jaman Belanda. Khusus untuk teh rakyat mulai dikembangkan sekitar Tahun 1980-an sehingga kondisi tanaman pada umumnya merupakan tanaman tua/rusak dengan produktivitas yang sudah menurun dan sudah saatnya dilakukan perbaikan budidaya melalui rehabilitasi dan intensifikasi tanaman. Perkembangan areal tanaman teh di Indonesia terus menurun sejak Tahun 2000, sehingga pada Tahun 2016 hanya tersisa seluas 117,27 ribu ha dengan sebagian besar (45,52\%) diusahakan oleh

Perkebunan Rakyat sedangkan sisanya diusahakan oleh Perkebunan Besar Negara $(30,47 \%)$ dan Perkebunan Besar Swasta (24,01\%). Menurunnya agroindustri teh Indonesia 
kini terjadi karena belum dapat diatasinya masalah-masalah yang dihadapi oleh teh Indonesia, seperti rendahnya produktivitas tanaman karena dominannya tanaman teh rakyat yang belum menggunakan benih unggul, terbatasnya penguasaan teknologi pengolahan produk dan belum mampunya petani mengikuti teknologi yang telah direkomendasikan (Good Agriculture Practice/GAP dan Good Manufacture Process/GMP) serta standar kualitas produk sebagaimana disyaratkan oleh ISO.

Perkembangan produksi teh di Indonesia pada periode 1980-2017 cenderung meningkat dengan rata-rata pertumbuhan sebesar 1,19\% per tahun. Tahun 1980-2012 rata-rata pertumbuhan produksi teh naik sebesar $1,31 \%$ per tahun sedangkan dalam kurun lima tahun terakhir (20132017) rata-rata pertumbuhannya hanya naik $0,41 \%$ per tahun. Total produksi teh di Indonesia pada Tahun 1980 sebesar 106 ribu ton tahun dan meningkat menjadi 144 ribu ton di Tahun 2016, sedangkan berdasarkan hasil estimasi Ditjen Perkebunan pada Tahun 2017 diperkirakan produksi teh sebesar 146 ribu ha (naik 1,49\%). Produksi teh tertinggi dicapai pada Tahun 2003 yaitu sebesar 170 ribu ton atau naik 2,80\% terhadap Tahun 2002.

Banyak jenis minuman yang ada di dunia, teh masih dianggap sebagai salah satu minuman terbaik dengan beragam khasiat. Masyarakat Indonesia mungkin lebih dikenal dengan speciality coffee. Sama halnya dengan kopi, industri teh dunia juga mengenal speciality tea alias teh unggulan. Speciality tea adalah teh yang melalui proses spesial di mulai dari penanaman, pemetikan, dan pemoresesan sehingga punya karakteristik teh yang berbeda.

PT SILA Agri Inovasi ("SAI") memiliki gagasan membuka usaha di bidang inovasi produk hasil pertanian Indonesia khususnya Speciality tea didasari oleh : Lemahnya inovasi di bidang hasil pertanian Indonesia Nilai tambah baik berupa pendapatan dan keuntungan usaha ada di industri hilir yang berbasis inovasi Pengalaman para pendiri di berbagai perusahaan industri hilir menjadi asset intelektual bagi usaha ini. SAI saat ini berdomisili di Kp. Babakan Jengkol , RT.003 RW.001, Desa Sumur Batu, Kecamatan Babakan Madang, Kabupaten Bogor, Jawa Barat 16811. Sesuai dengan pasal 3 Anggaran Dasar, maksud dan tujuan didirikannya SAI adalah pembangunan, jasa, perdagangan, industri, pengangkutan, pertanian, dan percetakan. Saat ini SAI bergerak di bidang perdagangan umum dan jasa dalam bidang bahan makanan dan minuman hasil pertanian, dan memproduksi Specialty Tea dengan merk dagang "SILA".

\section{Susunan Pengurus SAI}

Adapun susunan pengurus SAI adalah sebagai berikut :

\section{Dewan}

Komisaris

Komisaris

Utama : Iriana Ekasari

Komisaris : : Redha Taufik Ardias

Dewan

Direksi

Direktur : Ir. Dwi Putri Yanthi Muazd 
Pertumbuhan jumlah cafe di Indonesia sangat pesat. Berdasarkan data dari riset Euromonitor yang dikutip oleh USDA Foreign Agriculture Service mengatakan bahwa jumlah cafe/bar dan independent coffeeshop di Indonesia tahun 2016 sudah sekitar 6000 outlets dengan nilai bisnis secara berturut-turut adalah 3 Triliun Rupiah di Specialist Coffee Shop dan 30 Triliun Rupiah di sektor cafe/Bars. Pertumbuhan baik secara jumlah outlet maupun secara nilai penjualan terjadi lebih besar di jenis outlet Specialis Coffee Shop.



Gambar 1. Jumlah dan Pertumbuhan Ritel Food Service di Indonesia Tahun 2017

Dari data di atas dapat dilakukan perhitungan nilai transaksi dan berapa transaksi per hari dengan asumsi cafe buka selama 350 hari dalam 1 tahun sebagai berikut :

- Omset harian rata-rata/outlet: Rp. 30,2 Triliun : 5106 : 350 Hari Operasional = Rp16.899.000/hari (= Rp. 17 juta/hari)

- Jika rata-rata belanja pengunjung adalah Rp100.000/kunjungan, maka rata-rata setiap harinya outlet melakukan 170X transaksi (= 170 Tamu)/hari.

Data lain menunjukkan konsistensi yang sama, yaitu rata-rata jumlah pengunjung/hari/outlet adalah 150 - 170 pengunjung dan rata-rata nilai transaksi diperkirakan akan naik dari USD 14.10 di tahun 2014 menjadi USD 17.04 di tahun 2019.

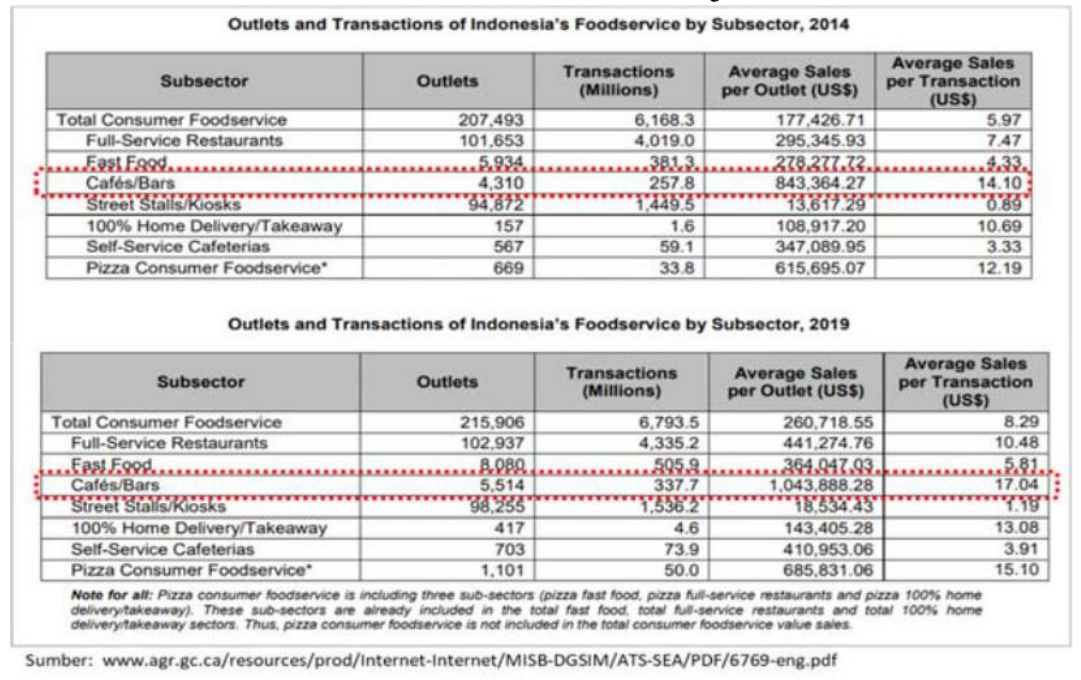

Gambar 2. Jumlah Outlet dan Transaksi Yang Terjadi di Setiap Jenis Outlet 
Sebagai negara muslim, pilihan minuman di cafe dan resto akan berkisar pada kopi, teh, jus buah, dan air mineral. Konsumen yang telah dapat menerima keberadaan specialty coffee dengan harga yang tinggi akan lebih mudah meneriam konsep adanya specialty tea pada konteks konsumsi di cafe bersama dengan kehadiran specialty coffee. Bagi operator cafe kehadiran specialty tea akan menjadi sumber revenue kedua setelah kopi. Hasil riset saat ini menunjukkan preferensi yang belum begitu baik untuk teh karena saat ini yang ditawarkan di cafe adalah teh biasa yang juga tersedia di supermarket, sehingga tidak ada diferensisasi produk, dan tentu saja konsumen enggan membayar lebih mahal untuk itu.

\section{Pasar Ekspor}

Pasar utama ekspor Indonesia dulu adalah Inggris, Jerman, Belanda, Rusia, Timur Tengah. Pasar-pasar ini telah berubah selera dan gaya hidup konsumennya. Mereka lebih antusias terhadap gaya hidup sehat, terutama pasar Eropa yang usia rata-rata penduduknya berusia lanjut dan mereka punya daya beli sangat baik. Karena itu otoritas kesehatan Eropa semakin memperketat aturan yang menyangkut consumer health and safety; dan ini memberatkan produsen teh Indonesia termasuk PTPN sebagai eksportir terbesar komoditas teh nasional, dengan berbagai persyaratan sertifikasi dan uji-uji lab yang mahal biayanya. Selain itu kosumen yang memiliki daya beli semakin membaik menginginkan teh spesial yang dinamakan Specialty Tea. Di Amerika pasar Specialty Tea pada tahun 2014 dilaporkan memiliki pangsa pasar sekitar 17,5\%. Besarnya pasar global specialty tea, menurut Transparency Market Research akan bertumbuh dari US\$ 12,8 milyar di tahun 2017 menjadi US\$20milyar di tahun 2025.

\section{Kompetisi di Specialty Tea - Indonesia}

Belum banyak brand yang masuk di segmen specialty tea. Beberapa diantaranya adalah:

Savis

Havel tea

Havilla



Gambar 3. Speciality Tea di indonesia 
Havilla berasal dari Bandung, model bisnisnya adalah melayani cafe dan resto. Banyak menggunakan teh dari Sri Lanka, China dan India. Tisanne juga impor. Havel Tea berasal dari Surabaya. Bisnis model sama dengan Havilla. Savis berasal dari Solo. Model bisnisnya adalah dengan memasarkan via Supermarket, membuka gerai di Hotel berbintang lima dan via saluran online. Kesamaan dari ketiga pemain ini adalah kemapuan meracik teh dan bahan lainnya sehingga menghasilkan keunikan pada rasa dan aroma.

Belum ada data yang dapat menjelaskan berapa nilai bisnis dari masing-masing pemain ini, dari ketiganya Havilla adalah yang paling banyak follower Instagrammnya dan yang paling banyak posting outlet pelanggannya. Kelemahan dari pemain yang ada, adalah mereka mengandalkan teh dari luar negeri yang harus diimpor dan tidak bisa memesan dalam jumlah kecil. Sehingga freshness teh sudah berkurang. Selain itu terjadi beban biaya persediaan yang tinggi. Selain itu tisane yang dipakai bukan hasil mengembangkan sendiri, sehingga bergantung pada pihak pemasok yang umumnya juga dari luar negeri.

Pertumbuhan brand specialty tea yang hampir seluruh bahan bakunya impor akan memperbesar nilai impor Indonesia dan menekan perbaikan kondisi teh dalam negeri. Ketergantungan pada impor yang besar, menimbulkan resiko usaha: Out of stock apabila terjadi gangguan logistik pada supply chain. Baik Havilla, Havel Tea maupun Savis belum terlihat adanya upaya membangun brand masing-masing menjadi brand ritel yang memiliki brand positioning yang jelas. Ketiganya masih "product oriented".

\section{KAJIAN PUSTAKA}

\section{Brand}

Merek (brand) adalah segala sesuatu yang terkait dengan perusahaan, produk, atau layanan. Merek bukan sekedar logo atau nama perusahaan, melainkan image atau persepsi seseorang tentang produk atau perusahaan. Dalam meningkatkan kekuatan mereknya, perusahaan akan berusaha memperkenalkan merek perusahaan karena keberadaan merek bukan hanya sematamata menunjukkan nama dari sebuah produk, namun lebih dari itu, merek menunjukkan nilai tambah dari produk, yang membedakan produk tersebut dengan produk lain.

Merek yang baik perlu dikelola dan diatur dengan baik pula. Maka dari itu diperlukan strategi merek yaitu sebuah manajemen yang mengelola elemen-elemen yang bertujuan untuk membangun sebuah merek. Strategi merek perusahaan dapat memperluas pangsa pasar dengan cara menanamkan nilai tambah sebuah produk atau jasa. Dalam strategi merek inilah fungsi PR sangat penting dalam melakukan komunikasi yang sesuai untuk menanamkan nilai perusahaan sehingga dapat menciptakan citra positif terhadap merek tersebut. Strategi merek ini menjadi penting karena dapat menjadi bagian dari strategi bisnis.

Menurut Kotler dan Keller, (2013:241) . Merek mengindetifikasi sumber atau pembuat produk dan memungkinkan konsumen bisa individual atau organisasi untuk menuntut tanggung jawab atas kinerjanya kepada pabrikan atau distributor tertentu.

$\mathrm{Xu}$ Yuanzhong dalam penelitiannya mengungkapkan bahwa strategi merek adalah bagian penting dari strategi perusahaan dimana dalam penerapan strategi merek yang efisien sangat penting bagi perusahaan untuk berhasil dari persaingan pasar dan dengan penggunaan fungsi PR yang efektif dapat menerapkan strategi merek yang sukses (Yuanzhong, 2005).

Dalam penelitian lainnya mengungkapkan bahwa strategi merek yang muncul dalam paradigma praktik untuk bersaing dalam era yang dipimpin oleh konsumen, merek dapat 
menjadi wadah untuk melibatkan konsumennya melalui nilai-nilai perusahaan yang ditawarkan sehingga membangun persepsi positif di benak konsumen mengenai produk atau perusahaan tersebut (Abimbola, 2010).

\section{Pengertian Implementasi strategi}

Implementasi strategi adalah proses dimana manajemen mewujudkan strateginya dalam bentuk program, prosedur dan anggaran. Implementasi strategi juga dapat diartikan sebagai pengembangan strategi dalam bentuk tindakan. Dengan keterampilan intuitif dan analitis yang baik, motivasi, dan kepemimpinan khusus serta mampu melakukan banyak koordinasi.

Implementasi terkadang lebih sulit karena implementasi membawa sebuah perubahan. banyak faktor-faktor tak terduga yang bisa menjadi hambatan. Hitt, Ireland, dan Hoskisson (2000) menekankan bahwa serangkaian tindakan strategis yang disebut formulasi strategi dan implementasi strategi harus disatukan dengan hati-hati jika perusahaan ingin mencapai daya saing strategis dan menghasilkan pendapatan di atas rata-rata. Kesuksesan persaingan terjadi ketika perusahaan menggunakan perangkat dan tindakan implementasi secara konsisten dengan strategi-strategi level-bisnis, level-perusahaan, akuisisi, internasional, dan kerjasama yang sebelumnya dipilih.

Perumusan strategi dan implementasi strategi harus sesuai dengan tujuan strategis dan misi strategis. Tujuan strategis dan misi strategis disusun berdasarkan informasi yang diperoleh dari analisis lingkungan eksternal dan lingkungan internal. Perusahaan mempelajari lingkungan eksternal dan internal agar dapat mengidentifikasi peluang-peluang dan ancaman pasarnya dan menentukan bagaimana menggunakan kompetensi-kompetensi intinya dalam usaha mendapatkan hasil strategisnya yang diinginkan. Dengan pengetahuan ini, perusahaan membentuk tujuantujuan strategis, misi strategis mensefisikasi, secara tertulis, produk-produk yang ingin diproduksi oleh perusahaan tersebut dan pasar yang ingin dilayani ketika mendayagunakan sumber daya, kapabilitas, dan kompetensi-kompetensinya.

\section{Specialty Tea}

Specialty Tea belum didefenisikan secara resmi. Referensi yang dapat digunakan dari International Specialty Tea Association, yang mana menerangkan bahwa ada 12 jenis standar yang harus dipenuhi untuk dapat dikategorikan sebagai Specialty Tea yaitu:

1. Kondisi daun pada saat dipanen: utuh dan murni

2. Mutu petik dan

3. Keseragaman mutu daun

4. Origin (Asal tempat tumbuh)

5. Tanggal Panen

6. Jenis kultivar (klon)

7. Pembuat Teh: Jelas pembuatnya dapat ditelusuri

8. Standar Pengolahan

9. Kadar Air

10. Warna

11. Aroma

12. Rasa

Selain hal di atas, penambahan bahan lain pada teh yang menjadikan cita rasa, aroma dan keunikan pada teh dapat dikategorikan sebagai specialty tea. 


\section{METODE PENELITIAN}

Salah satu jenis penelitian kualitatif deskriptif adalah berupa penelitian dengan metode atau pendekatan studi kasus (CaseStudy). Menurut Arikunto (2013), metode penelitian adalah cara yang digunakan peneliti dalam dalam mengumpulkan data penelitian. Penelitian kualitatif adalah suatu penelitian yang menghasilkan data yang bersifat deskriptif (penggambaran yang berupa kata-kata tertulis maupun lisan dari setiap perilaku orang-orang yang diamati). Nawawi (2003) mengemukakan bahwa "data studi kasus dapat diperoleh dari semua pihak yang bersangkutan, dengan kata lain data dalam studi ini dikumpulkan dari berbagai sumber". Sebagai sebuah studi kasus maka hasil penelitian ini hanya berlaku pada kasus yang diselidiki.

\section{HASIL DAN PEMBAHASAN}

Brand positioning SILA telah diriset kepada responden secara online melibatkan 300 responden dengan penajaman positioning. Berikut adalah hasil penelitian primer SILA melalui online terhadap 300 responden:



Gambar 4. Quisioner Brand Positioning SILA

Dapat dikatakan bahwa positioning yang ditawarkan brand SILA dengan spontan menarik peminat/pembeli sebanyak $24 \%$ pria dan $22 \%$ wanita. Sebagian besar responden membutuhkan bantuan penjelasan dari pelayan di cafe dan alat bantu komunikasi di cafe. Di sinilah pentingnya peran edukasi SILA kepada pemilik dan operator di cafe. Edukasi diberikan melalui tatap muka langsung maupun melalui video tutorial yang ditayangkan melalui sosial media. Harga yang pantas untuk brand SILA ini adalah Rp, 25,000/sajian, harga yang setara dengan brand internasional. Ini menunjukkan bahwa citra brand SILA setara dengan brand internasional.

Melihat kondisi persaingan dan peluang yang ada SILA hadir memberikan alternatif baru kepada konsumen: Generasi Millennial \& Z dan Wisatawan asing yang membutuhkan teh khas Indonesia "SILA". Value Proposition SILA adalah:

1. Product: Indonesian authentic high quality tea.

2. Promise: Good People. Good Leaf. Good Life.

Strategi usaha terdiri dari serangkaian pilihan strategis mulai dari pemilihan posisi perusahaan pada rantai nilai industri yang telah ada, model usaha sebagaimana tergambarkan pada canvass model dan strategi usaha untuk 5 tahun pertama masa operasional perusahaan. Strategi usaha ini didasarkan pada Key Success Factors (KSF). 


\section{Key success factors}

Untuk sukses di industri specialty tea (sebagaimana umumnya consumer goods industry)

dibutuhkan hal-hal sebagai berikut:

1. Brand dengan positioning yang jelas

2. Kapabilitas Pemasaran

3. Kapabilitas Inovasi

4. Kapabilitas Sales (Penjualan)

5. Integrasi dengan pasokan dari kebun

6. Dukungan Finansial

PT. SILA Agri Inovasi didirikan untuk mengisi posisi sebagai integrator antara produsen bahan baku teh dan kebutuhan pasar. Usaha utamanya adalah menggali dan memahami kebutuhan konsumen (pasar), menerjemahkan keinginan pasar menjadi produk inovatif, mengintegrasikan produsen bahan baku untuk membuat bahan baku produk inovatif dan membayar dengan fair trade kepada produsen, memasarkan dan menjual produk inovatif kepada konsumen, mengelola Customer Management dan rantai distribusinya. Gambaran posisi SAI pada rantai nilai dan model usaha dapat dilihat pada diagram berikut.

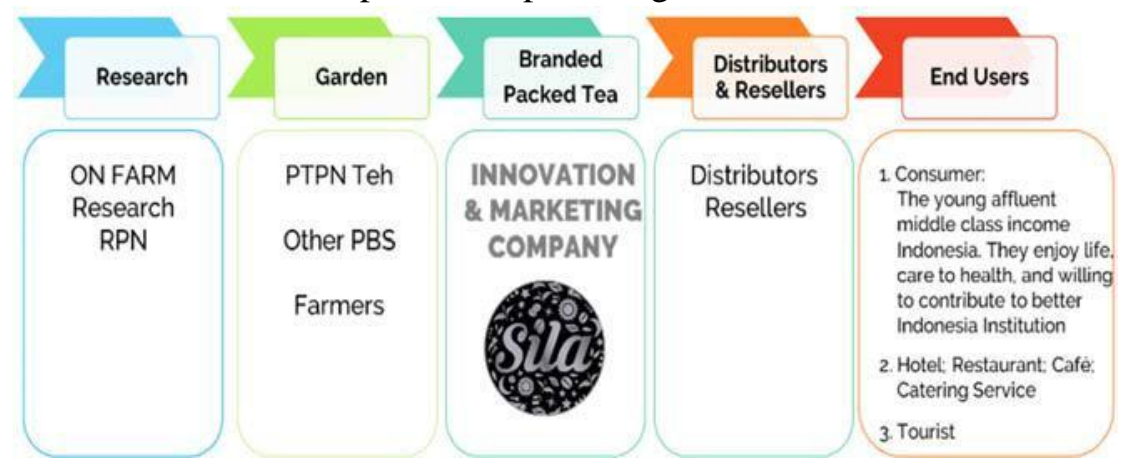

\section{Gambar 5. Posisi PT. SILA Agri Inovasi pada rantai nilai industri teh Indonesia}

SAI merupakan pelopor di Indonesia, dimana mulai dari research hingga end user. Keunggulan kompetitif SAI ada pada kekuatan brand SILA yang terus menerus membangun relevansi dengan generasi Millennial dan $\mathrm{Z}$ dengan produk inovatif menggunakan hanya bahan baku teh Indonesia dan cara-cara pemasaran yang sesuai, kemampuan melayani pasar dalam negeri: HOREKA dan gift shop dan pasar ekspor dengan sistim multi distributor.

\begin{tabular}{|c|c|c|c|c|c|}
\hline \multirow{2}{*}{$\begin{array}{l}\text { Key Partners } \\
\text { - } \text { Farmers } \\
\text { - Raw Material } \\
\text { JPackaging } \\
\text { Suppliers } \\
\text { - } \text { Toll } \\
\text { manufacturer } \\
\text { - } \text { Logistic } \\
\text { Company } \\
\text { - Culinary } \\
\text { Institution } \\
\text { - Media } \\
\text { - Communities } \\
\text { - Education } \\
\text { Institution }\end{array}$} & $\begin{array}{l}\text { Key Activities } \\
\text { - Product } \\
\text { Innovation } \\
\text {. Production } \\
\text { - Marketing } \\
\text { - }\end{array}$ & $\begin{array}{l}\text { Value Proposition } \\
\text { Good People } \\
\text { Good Leaf } \\
\text { Good Life }\end{array}$ & $\begin{array}{l}\text { Relatio } \\
\text { - Own S } \\
\text { IG, fb, } \\
\text { - Comm } \\
\text { Educati } \\
\text { - Exhibiti } \\
\text { - Digital } \\
\text { Critateh }\end{array}$ & $\begin{array}{l}\text { hip } \\
\text { ial Media: } \\
\text { utube } \\
\text { ity } \\
\text { mpaign: }\end{array}$ & $\begin{array}{l}\quad \text { Customer } \\
\text { OUR CONSUMERs } \\
\text { are the Millennials } \\
\text { and Gen Z café } \\
\text { goers and social } \\
\text { person, who care } \\
\text { about health, } \\
\text { environment, and } \\
\text { also proud to be } \\
\text { Indonesian }\end{array}$ \\
\hline & $\begin{array}{l}\text { Key Resources } \\
\text { - Right People } \\
\text { - Right } \\
\text { Technology } \\
\text {. Financial }\end{array}$ & $=$ & 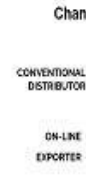 & 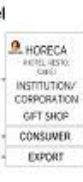 & 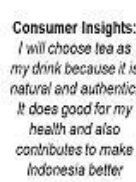 \\
\hline $\begin{array}{l}\text { Cost Driver } \\
\text { - Product (COGS) } \\
\text { - People } \\
\text { - Marketing \& Sales }\end{array}$ & $\begin{array}{l}\text { - CAPEX } \\
\cdot \text { System } \\
\cdot \text { Office Equipment }\end{array}$ & $\begin{array}{l}\text { Revenue } \\
\text { : Pro } \\
\text { - Pla } \\
\text { - Tea }\end{array}$ & $\begin{array}{l}\text { an } \\
\text { t sales: Fr } \\
\text { ion Trip } \\
\text { re }\end{array}$ & cy of pur & e \& Rp/Transaction \\
\hline
\end{tabular}

Gambar 6. Model Usaha PT. SILA Agri Inovasi 
Berdasarkan model usaha SAI untuk menjawab isu strategis yang dihadapi pada 5 (lima) tahun pertama operasionalnya, maka strategi usaha ditetapkan sebagaimana tertuang pada gambar di bawah ini.

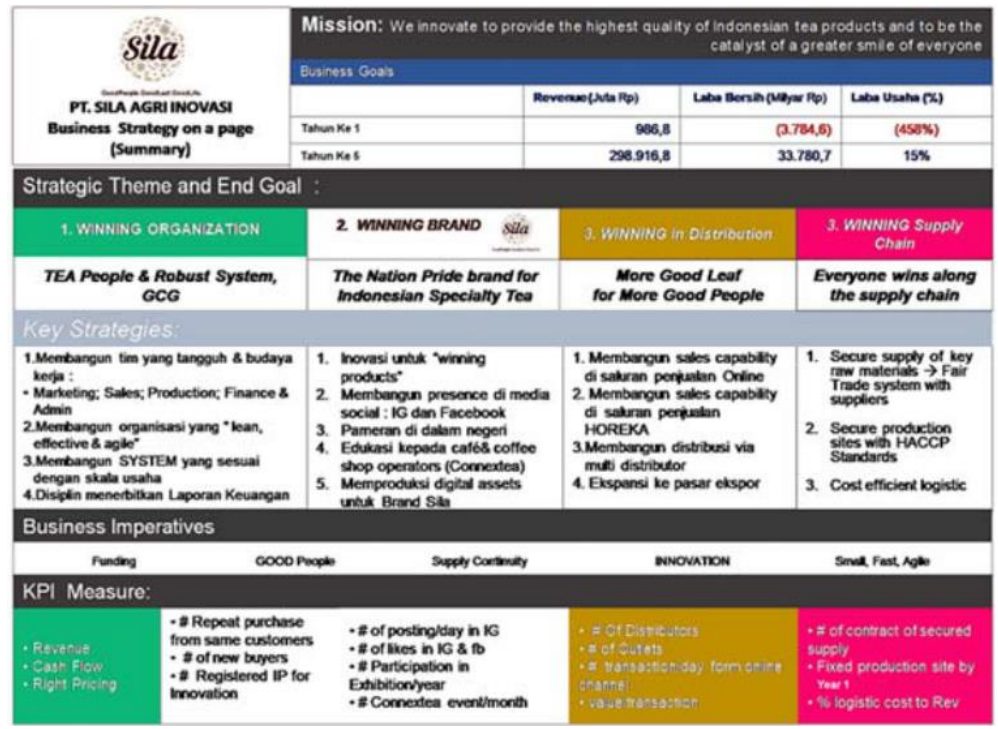

Gambar 7. Stategi Usaha PT. SILA Agri Inovasi 5 Tahun

Adapun Strategi PT SILA Agri Inovasi yang dijalankan dalam memenangi persaingan adalah sebagai berikut :

\section{$>\quad$ Strategi I - Winning Organization}

Membangun organisasi merupakan hal dasar yang mutlak harus dijalankan untuk menjalankan operasional perusahaan.

Inisiatif strategis meliputi:

1. Membangun tim yang tangguh \& budaya kerja:

Marketing; Sales;

Production;

Finance \& Admin

2. Membangun organisasi yang "lean, effective \& agile"

3. Membangun system yang sesuai dengan skala usaha

4. Disiplin menerbitkan Laporan Keuangan

\section{$>\quad$ Strategi II - Winning Brand}

Membangun pasar teh special adalah dengan membangun brand yang relevan dengan target pasarnya. Sebagaimana tercantum dalam Key Success Factors industri hilir. Positioning brand SILA telah diriset dan disukai oleh target pasar-sebagaimana telah diuraikan pada Bab II.

Untuk ini inisiatif strategis yang akan dijalankan adalah:

1. Inovasi untuk "winning products"

2. $\quad$ Membangun presence di media social : IG dan Facebook

3. Pameran di dalam negeri 
4. $\quad$ Edukasi kepada cafe\& coffee shop operators (Connextea)

5. Memproduksi digital assets untuk Brand SILA

\section{> Strategi III - Winning in Distribution}

Untuk melayani pasar dibutuhkan sistim disribusi yang sesuai. SAI memilih secara strategis model distribusi menggunakan sistim multi distributor, dengan pola ini maka kecepatan layanan kepada pasar dapat cepat terjadi. Pemilihan istributor diutamakan yang telah memiliki kesamaan pelanggan, yaitu HOREKA sebagai segmen gerai strategis. Ritel gerai souvenir (gift shop) merupakan pelanggan strategis lainnya yang harus dilayani oleh distributor. Penjualan langsung kepada konsumen Millennial dan $\mathrm{Z}$ dilakukan dengan membuka official store pada platform ecommerce. Setelah membangun pasar di dalam negeri, pasar ekspor untuk specialty tea khas Indonesia juga menjadi sumber pertumbuhan usaha.

Inisiatif strategis meliputi:

1. Membangun sales capability di saluran penjualan Online

2. Membangun sales capability di saluran penjualan HOREKA

3. Membangun distribusi via multi distributor

4. Ekspansi ke pasar ekspor

\section{$>\quad$ Strategi IV - Winning in Supply Chain}

Untuk memastikan kelangsungan usaha, harus pula dipastikan Supply Chain yang efesien meliputi inbound dan outbound mulai dari supply bahan baku hingga distribusi produk. Inisiatif strategis meliputi:

1. $\quad$ Secure supply of key raw materials $\rightarrow$ Fair Trade system with suppliers

2. Secure production sites with HACCP Standards

3. Cost efficient logistic

Adapun Taktik PT SILA Agri Inovasi untuk menjalankan strategi yang akan dilakukan adalah sebagai berikut :

\section{$>\quad$ Tactic Strategi I - Winning Organization}

\section{Struktur Organisasi}

Struktur organisasi minimal yang dibutuhkan adalah sebagai berikut:

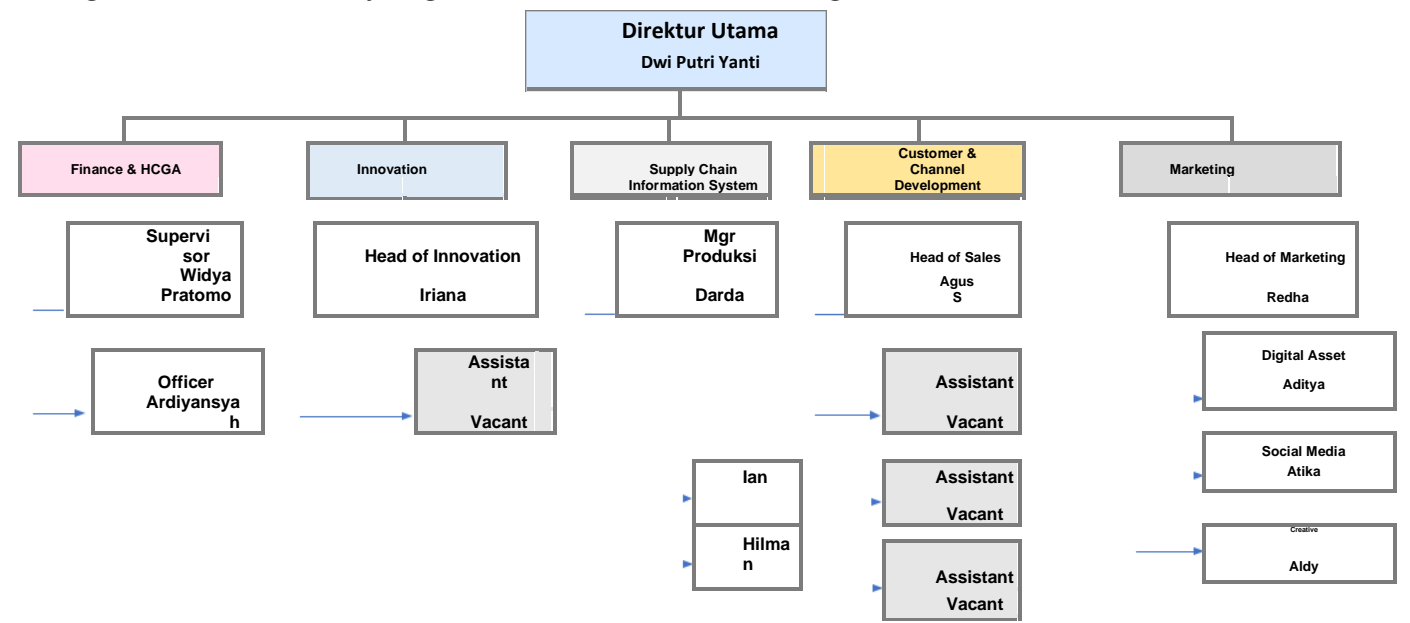

Gambar 8. Struktur Organisasi Stage 1 PT. SILA Agri Inovasi - Establishment 
Struktur dan besarnya organisasi akan menyesuaikan dengan kebutuhan pertumbuhan perusahaan.

\section{$>\quad$ Tactic Strategi II - Winning Brand}

Inovasi untuk "winning products"

Sebagai langkah strategis membangun kredibilitas brand, maka dikeluarkan 11 varian produk teh kering kemasan dan 3 varian RTD yang mengisi pilar arsitektur brand.

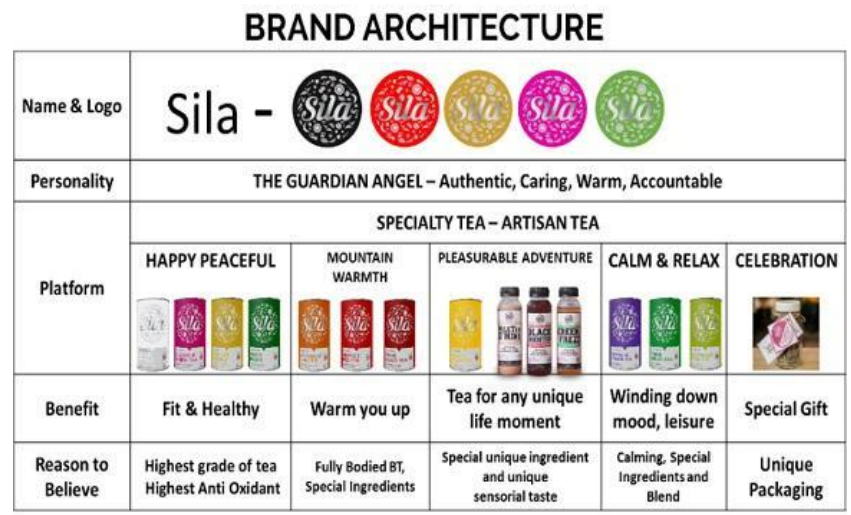

Gambar 9. Brand Arsitektur SILA

Varian produk teh kering kemasan tersebut ditawarkan dalam 3 jenis tipe kemasan:

Sachet Pouch

Cannister (kaleng)

Kemasan Suvenir (gift)

Executive Set (Corporate gift)

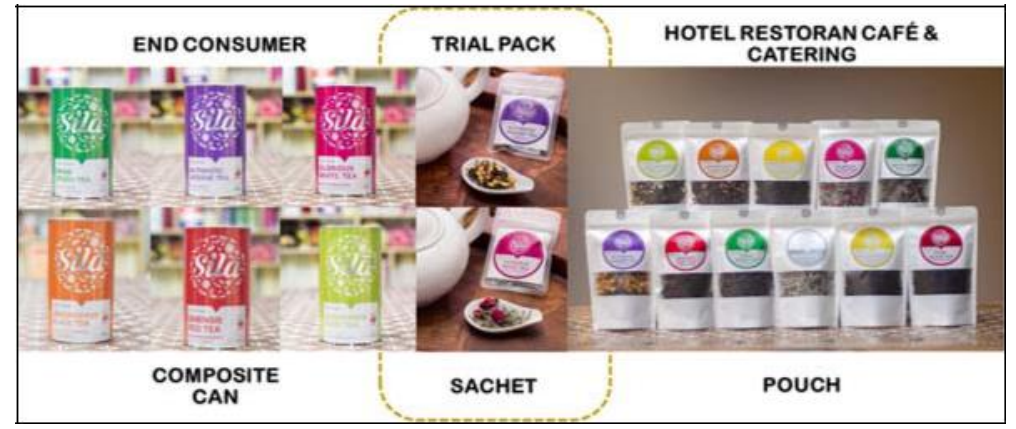

Gambar 10. Tipe kemasan yang ditawarkan

Sedangkan produk RTD dikemas dalam 1 ukuran botol $250 \mathrm{ml}$.

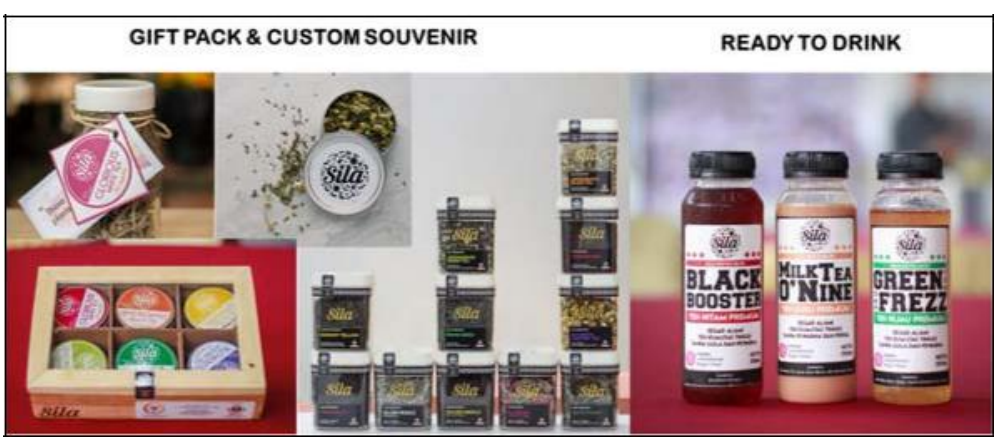

Gambar 11. Tipe kemasan souvenir dan RTD 


\section{Tactic Strategi III - Winning in Distribution}

1. $\quad$ Membangun sales capability di saluran penjualan Online

- $\quad$ Q1 Tahun ke 1- membuka gerai (toko) online di Tokopedia. Membuka toko online ini mempunyai nilai strategis:

a. Sebagai pemberi referensi harga kepada distributor, Reseller ataupun konsumen langsung

b. Sebagai media publikasi brand SILA dan hasil inovasi (produk) kepada masyarakat sebagai prasyarat untuk mengajukan hak cipta (HAKI) ke pihak otoritas HAKI.

2. $\quad$ Membangun sales capability di saluran penjualan HOREKA

- $\quad$ Q3 Tahun ke 1 - Rekrutmen pelaksana penjualan (Product expert) - Bali \&

Bandung

- Q1 Tahun ke 2 - Rekrutmen pelaksana penjualan (Product expert) Jakarta \& Bali

- $\quad$ Q2 Tahun ke 2 - Rekrutmen pelaksana penjualan (Product Expert) Surabaya

- Q4 Tahun ke 2 - Rekrutmen pelaksana penjualan (Product Expert) Medan

- $\quad$ Tahun ke 3 sampai dengan Tahun ke 5 - Outlet expansion

3. Membangun distribusi via multi distributor Rencana kegiatan untuk inisiatif strategis ini adalah:

- $\quad$ Q3 Tahun ke 1 - Seleksi dan rekrutmen distributor untuk Bandung dan Bali

- $\quad$ Q4 Tahun ke 1 - Penjualan kepada HOREKA di Bandung dan Bali melalui

distributor

- $\quad$ Q2 Tahun ke 2 - Menambah 2 distributor baru di Jakarta, 1 di Bali

- $\quad$ Q3 Tahun ke 2 - Menambah 1 distributor baru di Surabaya

- Q1 Tahun ke 3 - Menambah 1 distributor baru di Medan

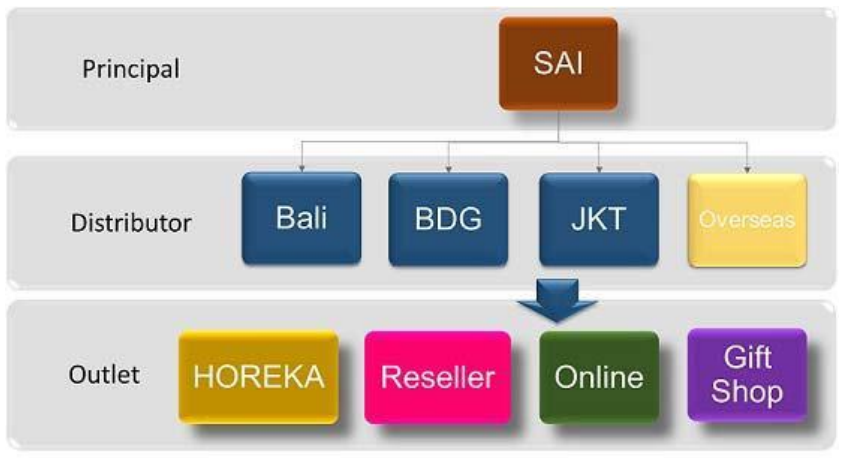

Gambar 12. Sistim Multi Distributorship

4. Ekspansi ke pasar ekspor

- Tahun ke 2 - Qatar

- Tahun ke 2 - Qatar + Malaysia + Amerika + Rusia

$>\quad$ Tactic Strategi IV - Winning in Supply Chain

1. $\quad$ Secure supply of key raw materials $\rightarrow$ Fair Trade system with suppliers

- Q3 Tahun ke 1 - Membuat perjanjian kepastian pasokan dengan pemasok: RPN, Indo Global Prima, PTPN

2. Secure production sites with HACCP Standards

- $\quad$ Q3 Tahun ke 1 - Seleksi tempat produksi

- $\quad$ Q4 Tahun ke 1 - Mulai produksi di $3{ }^{\text {rd }}$ party manufacturing 
3. Cost efficient logistic

- Q1 Tahun ke 2 - Join forecast mulai dari penjualan - pasokan bahan baku

- Menerapkan kajian pareto setiap tahun guna mengurangi beban biaya inventory

dan operating cash flow

\section{Strategi Harga (Pricing Strategy) VS Brand Image}

Untuk mempercepat adopsi budaya meminum specialty tea, SILA membuat kombinasi strategi (Category Killer) yaitu: membangun brand image yang setara dengan TWG dan TWINNING dan memastikan keterjangkauan harga beli pelanggan. Keunggulan kompetitif ini dapat diwujudkan karena faktor kedekatan lokasi dengan sumber bahan baku.



Gambar 13. SILA Image \& Pricing Positioning

1. Membangun presence di media sosial : Instagram dan

Facebook Tahun ke 1

$>\quad$ Penajaman strategi konten Instagram dan Facebook

$>\quad$ Fokus meningkatkan follower Instagram

Facebook Tahun ke 2 - Tahun ke 3

Memperbesar follower di Instagram dengan

$\begin{array}{ll}> & \text { Membuat } \text { event Connextea khusus bagi follower Instagram } \\ > & \text { Promosi khusus untuk follower Instagram } \\ & \text { mengkomunikasikan promosi penjualan pada ecommerce }\end{array}$

2. Pameran di dalam negeri

Event pameran di dalam negeri yang akan diikuti:

Bandung Tea festival - Tingkat Provinsi

INATEK - Tingkat Internasional SIAL -

Tingkat Internasional

Hari Perkebunan - Tingkat Nasional

Selain itu SAI akan mengadakan pameran sendiri di pusat -pusat perbelanjaan dimana banyak terkonsentrasi gerai makanan/cafe untuk membangun awareness dan sales kepada pengunjung cafe di pusat perbelanjaan dan edukasi langsung akan keunggulan brand SILA.

3. Edukasi kepada cafe \& coffee shop operators (Connextea)

CONNEXTEA adalah bentuk brand activation SILA untuk edukasi.

Targ

et $\quad$ : Cafe Operators, Komunitas (End Consumer)

Wakt

u : 2 kegiatan/Minggu

Ske : Berbayar sebagai pengganti biaya sampel teh dan sewa 
ma

tempat.

4. Memproduksi digital assets untuk brand

SILA Aset digital brand SILA berupa:

1. Foto yang diproduksi sendiri ataupun yang diunggah oleh komunitas/konsumen

2. Video yang diproduksi dan diunggah sendiri maupun yang diunggah oleh konsumen

3. Testimonial Pelanggan (percakapan digital yang positif tentang Sila)

4. Saluran (Channel) digital



Gambar 14. Instagram SILA

Unit fungsional pemasaran bertugas memperbanyak asset digital ini dengan agresif dan terintegrasi dengan kegitan pemasaran lainnya. Untuk membuat sinergi antar kegiatan lainnya SAI berencana untuk menunjuk satu biro iklan pemasaran yang memang ahli di bidang ini.

\section{KESIMPULAN DAN SARAN}

\section{Kesimpulan}

SAI dalam menerapkan strategi bersaing dengan para kompetitor untuk merebut pasar speciality tea yang belum dikenal luas di Indonesia, maka SAI harus melakukan berbagai strategi untuk menanamkan produk dengan brand SILA ke masyarakat agar brand SILA tersebut dapat selalu di ingat oleh masyarakat sebagai suatu brand speciality tea terbaik yang ada di Indonesia. SAI agresif dalam melakukan penetrasi pasar dengan strategi Winning Organization, Winning Brand, Winning in Distribution dan Winning in Supply Chain

Dalam menghadapi Pricing Strategy di dalam persaingan speciality tea, brand SILA harus membangun presence di media social : Instagram dan Facebook, pameran di dalam negeri, edukasi kepada café\& coffee shop operators (Connextea), dan memproduksi digital assets untuk brand SILA

\section{Saran}

1. SAI perlu melakukan peningkatan strategi brand positioning dengan sasaran pada pasar yang secara spesifik agar dapat mempertahankan keunggulan bersaing.

2. Selain itu SAI harus menjaga brand dan positioning dengan mengkomunikasikan secara intens bahwa SILA merupakan speciality tea terbaik di Indonesia. 
3. Pihak manajemen SAI harus memperhatikan hasil temuan ini dalam rangka meningkatkan strategi bersaing dan juga meningkatkan kemampuan strategi usaha agar dapat menghadapi persaingan yang ketat.

4. Perlu ada penelitian lanjutan yang terkait dengan objek penelitian ini atau variabel penelitian ini yang lebih diperluas lagi.

\section{DAFTAR RUJUKAN}

Abimbola, T. (2010). Brand strategy as a paradigm for marketing competitiveness. Journal of Brand Management, pp.177-179.

Agmasari, S. 2018. Mengenal "Speciality Tea" dan Peluangnya di Indonesia. https://ravel.kompas.com/read/2018/11/29/160500727/mengenal-speciality-tea-danpeluangnya-di-indonesia. (31 Maret 2020, jam 14.14)

Ali, Hapzi. 2020. Modul 1: Overview of Strategic Management. Jakarta: Universitas Mercu Buana.

Ali, Hapzi. 2020. Modul 5: Form and Implementation Strategyement. Jakarta: Universitas Mercu Buana

Ali, Hapzi; Mappesona. 2016. "Build Brand Image: Analysis Service Quality and Product Quality (Case Study at Giant Citra Raya)”. ISSN: 0972-9380

Anonim. (2020). The Pathway to a Definition for Specialty Tea.

https://specialtyteaassociation.org/the-definition-of-specialty-tea/.(31 Maret 2020, jam 23.00).

Arikunto, S. (2013). Prosedur Penelitian Suatu Pendekatan Praktik. Edisi Revisi. PT. Rineka Cipta. Jakarta https://www.instagram.com/haveltea/. (1 April 2020, jam 00.40). https://www.instagram.com/havilla tea/. (1 April 2020, jam 00.45). https://www.instagram.com/savis tea/?hl=id. (1 April 2020, jam 00.35). https://www.instagram.com/sila_tea/. (1 April 2020, jam 10.30).

Khotler Philip, Kevin Lane Keller. 2013. "Manajemen Pemasaran. Edisi ke 13 Jilid satu". Penerbit Erlangga. ISBN 978-0-13-600998-6.Jakarta.

Nawawi, Hadari, H. (2003). Manajemen Sumber Daya Manusia Untuk Bisnis Yang Kompetitif. Cetakan ke-7. Gadjah Mada University Press, Yogyakarta.

Rangkuti, Fahwani, Y. (2017). Indonesia: Food Service - Hotel Restaurant Institutional. https://apps.fas.usda.gov/newgainapi/api/report/downloadreportbyfilename?filename= Food\%20Service\%20-20Hotel\%20Restaurant\%20Institutional_Jakarta_Indonesia_06-122017.pdf. (31 Maret 2020, jam 23.30).

Yuanzhong, X. (2005). A study on the relationship between public relations and brand strategy. DiVa Portal. 